\title{
Consumer preference of reduced-sodium Tom Yum Goong seasoning powder as affected by powdered dried shrimp genres and quantity
}

\author{
Koohathong, S. and ${ }^{*}$ Khajarern, K. \\ Faculty of Interdisciplinary studies, Khon Kaen University, Nong Khai Campus, Nong Khai 43000 Thailand
}

\author{
Article history: \\ Received: 2 June 2021 \\ Received in revised form: 16 \\ July 2021 \\ Accepted: 18 October 2021 \\ Available Online: 28 \\ November 2021
}

Keywords:

Dried shrimp powder, Reduce sodium Tom Yum Goong seasoning powder, Consumer preferences

DOI:

https://doi.org/10.26656/fr.2017.5(6).390

\begin{abstract}
This research aimed to investigate how four different types and amounts of powdered dried shrimp (crispy dried shrimp, dried krill, dried white baby shrimp, and dried white shrimp) influenced consumer preferences for reduced sodium Tom Yum Goong seasoning powder. Three levels (1, 2 and $3 \%$ by weight) of each dried shrimp powder were combined with the Tom Yum seasoning powder (TYSP) reference recipe. Each recipe was prepared as a soup sample (The sample without dried shrimp powder as a control). The soup samples were then tested and assessed on 12 attributes using 96 consumer panels. The results revealed that the sample containing 3\% dried white shrimp powder performed significantly higher than the control in terms of liking in the categories of 'appearance', 'shrimp flavour intensity', 'palatability', 'natural taste' and 'overall', and 'willingness to pay'. Furthermore, the sample containing 3\% crispy dried shrimp powder had a significantly higher liking mean score for 'shrimp flavour intensity,' 'saltiness', and 'palatability' than the control. However, the sodium content of 3\% dried white shrimp powder $(435 \mathrm{mg} / \mathrm{L})$ was lower than that of $3 \%$ crispy dried shrimp powder $(440 \mathrm{mg} / \mathrm{L})$. Consequently, $3 \%$ powdered dried white shrimp was selected as an ingredient for reduced sodium Tom Yum Goong seasoning powder.
\end{abstract}

\section{Introduction}

Tom Yum Goong is a name of the famous Thai spicy soup (soup in Thai is called "Tom") which is characterized by mixing spices and herbs (mixing in Thai is called "Yum") such as chilli, galangal, shallots, lemongrass, and kaffir lime leaves (Kitsawad and Tuntisripreecha, 2016). Lime juice, sugar and sodium salt $(\mathrm{Na})$ are added for sour, sweet and salty taste, respectively. Monosodium glutamate is also utilized to improve umami taste (Suwankanit et al., 2015), and the last one is shrimp (named "Goong" in Thai), which is the most important ingredient (Gono, 2018).

Recently, marketed TYSP is developed in powder form (Siripongvutikorn et al., 2009; Phornphisutthimas, 2010). It has now been produced for ease of use while making Tom Yum soup. However, from a preliminary market survey, there was no Tom Yum Goong seasoning powder (TYGSP) available in the market. There are only TYSP products that do not indicate on their product label that they contain dried shrimp as an ingredient. While Tom Yum Goong seasoning products in a set or a paste form usually contain chilli paste, which contains dried shrimp as an ingredient but the type and quantity of dried shrimp used are not specified. Thus, the addition of dried shrimp powder to TYSP is the focus of this study in order to apply the research findings to use for the research of "influences of sodium salt reduction and replacement on consumer preference and sensory characteristics of Tom Yum Goong seasoning powder". Therefore, the genres and quantity of dried shrimp powder utilized are critical for the shrimp flavour improvement of reduced-sodium TYGSP for industrial applications.

Most manufactured dried shrimps that are sold domestically and internationally are made mostly of marine shrimp (Yamprayoon and Sukkho, 2006). Most dried shrimps are made from white shrimp (Pacific white or White leg shrimp; Litopenaeus vannamei) (Sukhontachart, 2013) which are found in a large amount along the inner Gulf of Thailand and the Andaman Sea (Kaewchamnong et al., 2011). The three forms of shrimp that have been sun-dried until they are very little for preservation reasons are shelled shrimp, shell-on shrimp, and tiny shell-on shrimp. (Zhu, 2018). As a flavour enhancer and important ingredient, it is integrated with many Thai and Asian cuisines, to impart unique umami 
and seafood-like taste (Department of Science Service, 2018; Zhu, 2018).

Lertsapthaweesin (2015) classified dried shrimp of the factory (Surat Dried Shrimp factory, Thailand) into 5 types for the context of uses. They are; (1) dried white shrimp (Shelled shrimp) is a dried white shrimp without head, tail and shell. It is only dried meat of shrimp that is more expensive than other types. Its cost is 125 baht per $100 \mathrm{~g}$, (2) dried flat shrimp is a dried shrimp without the head. It is called dried shell shrimp or dried slim shrimp. Its cost is 110 baht per $100 \mathrm{~g}$, (3) Dried white baby shrimp (Tiny shell-on shrimp) is a small size of dried whole shrimp. Its saltiness is less than dried krill. Its cost is 110 baht per $100 \mathrm{~g}$, (4) crispy dried shrimp (Shell-on shrimp) is a dried white shrimp without the head. Its saltiness is less than dried white baby shrimp. Its cost is 75 baht per $100 \mathrm{~g}$ and (5) the smallest dried entire shrimp is dried krill (scientific name Euphausiacea). It has a very salty flavour. It is priced at 105 baht per $100 \mathrm{~g}$. In this study, four varieties of dried shrimp powder were utilized to develop reduced-sodium TYGSP samples: dried white shrimp, dried white baby shrimp, crispy dried shrimp, and dried krill.

However, most of the dried shrimp products on the market have a high sodium salt content (Prasertwaree, 2005). This is because they are made from marine shrimps which have been boiled in brine again (Tirawanichakul et al., 2008). An elevated dietary intake of sodium salt is associated with hypertension, which is considered to be the main risk factor for cardiovascular diseases (Hendriksen et al., 2014) and kidney disease (Srisawat, 2020). World Health Organization (WHO) strongly recommends a reduction in dietary intake to $<2$ g sodium per day (or $<5 \mathrm{~g}$ salt per day) in adults (WHO, 2012).

The first challenge for dried shrimp powder addition into TYGSP is raising the sodium salt content. This may have an impact on saltiness level and consumer preference. Because each variety of dried shrimp powder has a different sodium salt content but may be distinguished by its distinct flavour. Thus it is interesting to investigate the effects of various dried shrimp types and their quantities on consumer preference of TYGSP using food sensory measurement to be used as a guideline for improvement and development of reducedsodium powdered Tom Yum Goong seasoning powder in the future.

\section{Materials and methods}

\subsection{Subjects}

Ninety-six consumer panels [Resurreccion (1998) recommended 50-100 consumer panel size for various consumer sensory testing laboratory] of which 52 females (mean age was 23.2 \pm 2.5 ) and 44 males (mean age was $23.4 \pm 2.1$ ) were recruited using purposive sampling to the sensory laboratory of Food Technology and Innovation Department, Khon Kaen University, Nong Khai Campus. They were students of the university. Individuals with food allergies especially to shrimp and monosodium glutamate were not approved to participate in this study.

\subsection{Samples}

A total of gour types of dried shrimp including crispy dried shrimp, dried krill, dried white baby shrimp and dried white shrimp were obtained from Surat dried shrimp factory, Thailand (Lertsapthaweesin, 2015). They were ground and sieved through a 250 mesh screen. All ingredients used in the reference TYGSP recipe (Khajarern et al., 2010) were shown in Table 1.

Table 1. TYSP reference recipe

\begin{tabular}{lc}
\hline Ingredients & $(\%)$ \\
\hline Salt & 25.0 \\
Fine sugar & 20.0 \\
Dry lemon grass powder & 5.0 \\
Chili paste powder & 2.0 \\
Dried chili powder & 2.0 \\
Dried shrimp & $1.0-3.0$ \\
Coconut powder & 20.0 \\
MSG & 15.0 \\
Lime powder & 4.0 \\
Galangal powder & 2.0 \\
Kaffir lime leave powder & 2.0 \\
\hline Source: Khajarern et al. $(2010)$ &
\end{tabular}

Before sensory testing, three different levels of each dried shrimp powder $(1 \%, 2 \%$ and $3 \%$ by weight) were fortified to the reference TYGSP recipe (moisture content $<14 \%$ ). In addition, the sample without dried shrimp powder was also prepared as a control. Therefore, 13 samples were prepared for the sensory test in this study. Before serving, all TYG samples were reconstituted using $500 \mathrm{~mL}$ boiling water. Some aliquot $(20 \mathrm{~mL})$ of each reconstituted TYGSP in a transparent plastic container with a lid cover was encoded with random three-digit numbers to avoid bias and then served to panellists. The temperature of all reconstituted TYGSP samples was controlled at $45 \pm 1^{\circ} \mathrm{C}$ by storing them in a hot cabinet. The temperature of a hot cabinet was checked using an infrared thermometer (GM320, temperature range of $-50-380^{\circ} \mathrm{C}$, calibrated with ice water at $0^{\circ} \mathrm{C}$ and boiling water at $100^{\circ} \mathrm{C}$ ).

\subsection{Method}

The Randomized Complete Block Design (RCBD) 
was assigned for arranging the test replications (Meilgaard et al., 2006). Each consumer panel had to test for 13 samples (3-4 samples per session) at different times to avoid sensory fatigue (each consumer panel was tested twice a day). Each of the samples was presented to an individual consumer panel for sensory evaluation. Before and after tasting each sample, individuals were rinsed to clean their palate with drinking water and a piece of white bread. Then they were subsequently asked to complete the scales in 3 parts including 1) sensory preference test, 2) sensory intensity test and 3) willingness to pay test, respectively. The temperature of the testing room was controlled at $25^{\circ} \mathrm{C}$.

To measure consumer preference, after serving each of the samples, consumer panels were asked to taste each sample and evaluate to what extent they liked or disliked each sample in 10 attributes; 'appearance', 'shrimp flavour intensity', 'saltiness', 'taste intensity', 'palatability', 'mouth feel', 'natural taste', 'authentic Tom Yum' and 'overall liking' using a nine-point hedonic scale $(1=$ disliked extremely, $5=$ neither liked nor disliked, 9 = extremely liked) (Meilgaard et al., 2006). For sensory intensity test as 'saltiness' and 'umami' levels, the sample was evaluated using the following 7- point Just About Right (JAR) scale (7 = much too high, $4=$ just about right and $1=$ much too low) (Popper, 2014). For an assessment related to the 'willingness to pay', consumers purchase intention was carried out regarding the samples. A five-point structured scale was used, in which 1 indicated that the consumers definitely would not buy; 2-the consumers would probably not buy; 3-the consumers may/may not buy; 4consumers would probably buy and 5-consumers would definitely buy (De Almeida et al., 2016).

A salinity salt tester meter (AZ 8371; AZ Instrument, Taiwan) was used for sodium chloride content analysis with a reading sodium chloride $(\mathrm{NaCl})$ range from 0 up to $9999 \mathrm{mg} / \mathrm{L}(\mathrm{ppm})$. In addition, a portable salinity refractometer meter (LH-Y28; Hangzhou Lohand Biological Technology Co., Ltd., Zhejiang, China) was used to recheck with a reading $\mathrm{NaCl}$ range from $0-28 \%$ (automatic temperature compensation range: $10-30^{\circ} \mathrm{C}$ ).

\subsection{Data analysis}

The data from all scales were analyzed using multivariate analyses of variance (MANOVA) $(p \leq 0.05)$ considering sample and block as sources of variation by SPSS/PC for Windows Version 26.0 developed by SPSS Inc., Chicago, USA. Pearson's correlation coefficients were utilized to determine the relationship between all of the attributes (Obilor and Amadi, 2018). Cronbach's alpha was calculated to test the experiment's reliability. The level of significance for all statistical analyses was set at 0.05 .

\section{Results and discussion}

The results are shown in Figure 1. It was found that the sample containing $3 \%$ dried white shrimp powder had significantly higher mean scores of liking in the categories of 'appearance' and 'palatability ( $p \leq 0.01)$, 'shrimp flavour intensity', 'palatability', 'natural taste' and 'overall', and 'willingness to pay' ( $p \leq 0.05)$. Furthermore, the sample containing 3\% crispy dried shrimp powder had a significantly higher to mean score for 'shrimp flavour intensity,' 'saltiness' and 'palatability'. However, the sodium content of $3 \%$ dried white shrimp powder $(435 \mathrm{mg} / \mathrm{L})$ was lower than that of $3 \%$ crispy dried shrimp powder (440 mg/L). As a consequence, $3 \%$ powdered dried white shrimp with low sodium levels and high 'overall liking' and 'willingness to pay' was chosen as an ingredient for reduced sodium TYGSP. The total sodium level of the sample containing $3 \%$ crispy dried shrimp powder (per $500 \mathrm{~mL}$ of water) was calculated to be around $1.5 \mathrm{~g}$ sodium, which was less than the $2 \mathrm{~g}$ sodium intake recommendation for adults per day (WHO, 2012). The dried white shrimp powder sample, on the other hand, was costly (125 baht/100 g), which may result in a higher product selling price. However mean overall liking and willingness to pay were considered, its overall liking was 7.1, indicating 'like moderately', while its willingness to pay was 3.9, suggesting 'would probably purchase'. This implies that the type and quantity of dried shrimp powder may need to be improved in the future.

Deesawas (2007) stated that Tom Yum seasoning in paste form combined with 3.3\% dried shrimp had also high acceptance for his research, as did Tom Yum Goong seasoning in paste form produced with $8 \%$ dried shrimp. However, the high amount of dried shrimp powder would increase the sodium content accordingly. In addition, Ngoenchai and Suwonsichon (2011) indicated that using 5\% of dried shrimp showed a high level of dried shrimp flavour but low acceptability for their Tom Yum seasoning in paste form. Therefore, in the next experiment the level of dried shrimp powder may need to be increased to between 3-5\%, but increasing the amount of powdered shrimp will also affect the sodium content.

According to the results, all samples were not significantly different from the control sample in terms of liking in 'taste intensity', 'mouth feel' and 'authentic Tom Yum', saltiness and umami levels. These might be owing to the fact that the majority of the ingredients were similar quantities of herbs and spices, with the exception of the type and quantity of shrimp utilized. As a result, these attributes of all samples were comparable. 

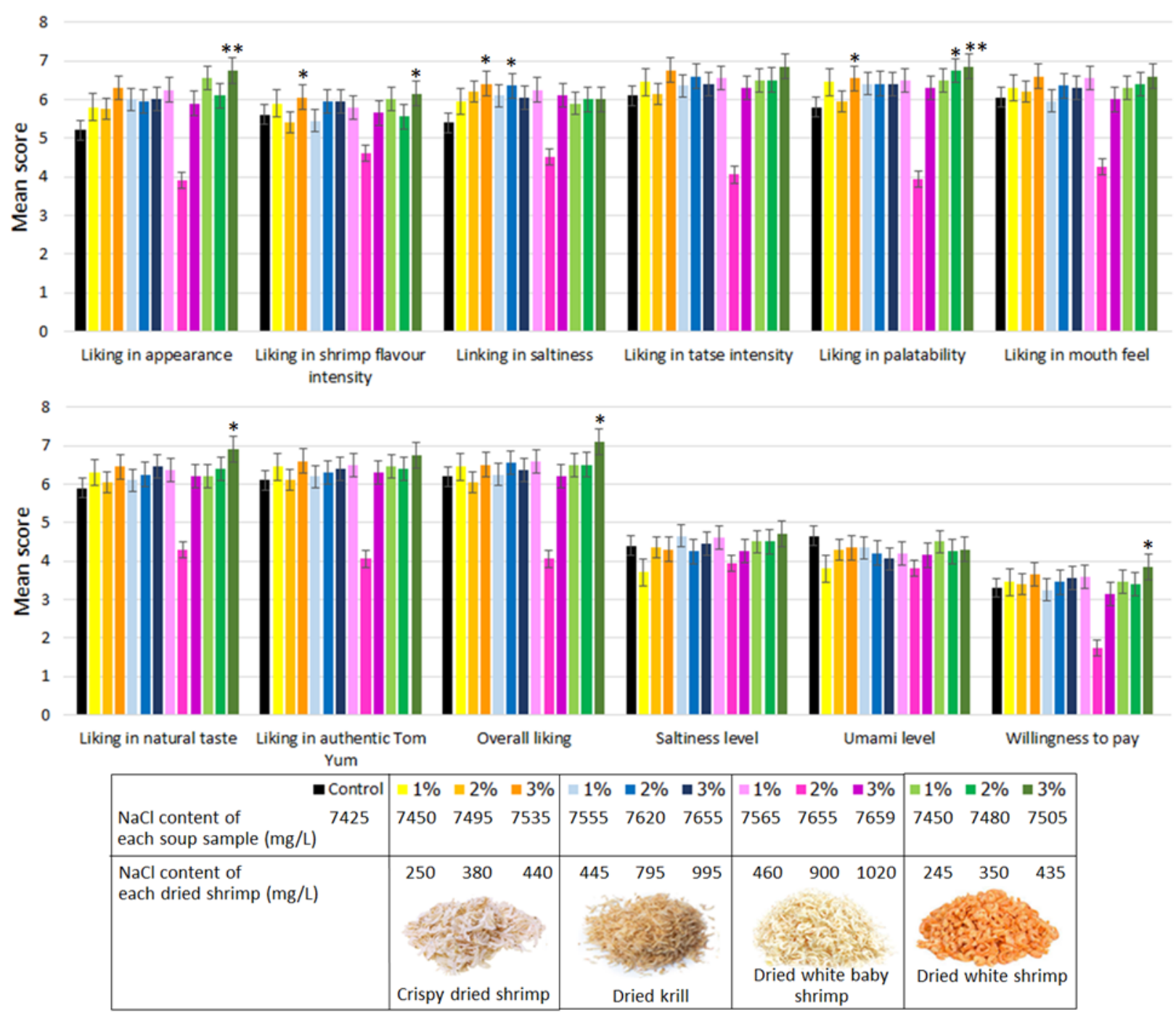

Figure 1. Effect of dried shrimp powder genres and quantities on 12 attributes of TYGSP.

*Higher than control significantly $(\mathrm{p} \leq 0.05),{ }^{*}$ Higher than control significantly $(\mathrm{p} \leq 0.01)$.

For guidelines for the next experiment, it was necessary to consider the correlation of all attributes. Table 2 presents the Pearson's correlation coefficients between all attributes. The overall liking is strongly associated with liking in shrimp flavour intensity and saltiness, palatability level and willingness to pay but weakly associated with saltiness level. In addition, willingness to pay is also associated strongly with liking in shrimp flavour intensity and saltiness, palatability level and overall liking but associated weakly with saltiness level. Therefore, using to increase the level of dried shrimp powder is to increase the salt level, which will affect the consumer's rejection of the purchase of reduced-sodium TYGSP.

The experiment's reliability of this sensory result was calculated as Cronbach's alpha $=0.957$. George and Mallery (2003) and Husebo et al. (2007) indicated that Cronbach's alpha over 0.9 was very high or reliable. After checking Cronbach's alpha if an item deleted of each attribute, there were no anomalous values discovered. It meant most of all consumer panels understood each of the attributes well. For the sample containing $2 \%$ dried white baby shrimp powder, it had lower mean scores of all attributes than all samples, it might be occurred by abnormalities in the sample preparation.

Table 2. Pearson's correlation coefficients between all attributes of TYGSP.

\begin{tabular}{lcc}
\hline Attributes & Overall & Willingness \\
\hline Liking in appearance & $0.62^{* *}$ & $0.40^{* *}$ \\
Liking in shrimp flavour intensity & $0.56^{* *}$ & $0.41^{* *}$ \\
Liking in saltiness & $0.64 * *$ & $0.57^{* *}$ \\
Liking in taste intensity & $0.85^{* *}$ & $0.62^{* *}$ \\
Liking in palatability & $0.88^{* *}$ & $0.62^{* *}$ \\
Liking in mouth feel & $0.82^{* *}$ & $0.54^{* *}$ \\
Liking in natural taste & $0.84^{* *}$ & $0.56^{* *}$ \\
Liking in authentic Tom Yum & $0.90^{* *}$ & $0.62^{* *}$ \\
Saltiness level & $0.15^{*}$ & 0.05 \\
Umami level & $0.15^{*}$ & 0.10 \\
Willingness to pay & $0.70^{* *}$ & $1.00^{* *}$ \\
\hline
\end{tabular}

* Correlation was significant at the 0.05 level (2-tailed), ** Correlation was significant at the 0.01 level (2-tailed). 
It is worth noting that dried krill and dried white baby shrimp had a higher level of $\mathrm{NaCl}$ adsorption than crispy dried shrimp and dried white shrimp of the same weight. This is probably due to the smaller surface contact areas, hence more $\mathrm{NaCl}$ from brine solution was absorbed. Consequently, their tastes were saltier (Phrigboonchan, 2011). There are various types of freshwater shrimp which were not used to reduce sodium in this research such as Lanchester's freshwater prawn (Macrobrachium lanchesteri) and giant freshwater prawn (Macrobrachium rosenbergii) (Whangchai et al., 2007) because they had not been manufactured as a commercial or industrial product. In the future, the aforementioned freshwater shrimp might be dried, converted to powder form, including the use of various sodium salt replacers, and compared to a sample containing $3 \%$ dried white shrimp powder of TYGSP.

\section{Conclusion}

Even though this was only food sensory research, it was important to screen the type and quantity of food ingredients as a dried shrimp powder for reduced sodium TYGSP development research in the next step. According to the findings of this research, $3 \%$ dried white shrimp powder was found that it was suitable for the development of reduced-sodium TYGSP. This is because most consumers accepted and intended to purchase high priced shrimp. Despite being more costly than other dried shrimp powders, it also contained low sodium salt levels.

\section{References}

De Almeida, M.A., Villanueva, N.D.M., Da Silva Pinto, J.S., Saldaña, E. and Contreras-Castillo, C.J. (2016). Sensory and physicochemical characteristics of reduced sodium salami. Scientia Agricola, 73(4), 347 -355. https://doi.org/10.1590/0103-9016-2015-0096

Department of Science Service (DSS). (2018). Quality Survey and Process of Dried Shrimp. Bangkok, Thailand: Department of Science Service.

Deesawas, U. (2007). Tom Yum Gung Paste. Bangkok: Rajamangala University of Technology Krungthep.

George, G. and Mallery, P. (2003). SPSS for Windows Step by Step: A Simple Guide and Reference 11.0 update. Boston, USA: Allyn and Bacon.

Gono, S.G. (2018). Development of Tom Yum Goong in Retort Pouch. Bangkok, Thailand: Assumption University.

Hendriksen, M.A.H., Hoogenveen, R.T., Hoekstra, J., Geleijnse, J.M., Boshuizen, H.C. and van Raaij, J.M.A. (2014). Potential effect of salt reduction in processed foods on health. The American Journal of
Clinical Nutrition, 99(3), 446-453. https:// doi.org/10.3945/ajen.113.062018

Husebo, B.S., Strand, L.I., Moe-Nilssen, R., Husebo, S.B., Snow, A.L. and Ljunggren, A.E. (2007). Mobilization Observation Behavior Intensity Dementia Pain Scale (MOBID): development and validation of a nurse-administered pain assessment tool for use in dementia. Journal of Pain and Symptom Management, 34(1), 67-80. https:// doi.org/10.1016/j.jpainsymman.2006.10.016

Kaewchamnong, T., Sungpud, C. and Buakong, S. (2011). Production and Shelf Life of Kung Kaew Product. Nakhon Si Thammarat, Thailand: Nakhon Si Thammarat Rajabhat University.

Kitsawad, K. and Tuntisripreecha, N. (2016). Sensory characterization of instant Tom Yum soup. KMUTNB International Journal Applied Science and Technology, 9(2), 145 - 152. https:// doi.org/10.14416/j.ijast.2016.02.001

Khajarern, K., Suwannasing, S. and Upahad, A. (2010). Palatability and sensory interaction between umami and other taste substances: a case of instant Thai spicy prawn soup (Tom Yum Kung), Presented at $1^{\text {st }}$ Academic Conference, Nongkhai, 2010. Nongkhai, Thailand: Khon Kaen University, Nongkhai Campus.

Lertsapthaweesin, T. (2015). Types of Dried Shrimp. Retrieved on October 24, 2019 from foodnetworksolution Website: http:// www.foodnetworksolution.com/webboard/ index.php?topic $=5553.0$.

Meilgaard, M., Civille, G.V. and Carr, B.T. (2006). Sensory Evaluation Techniques. $4^{\text {th }}$ ed. Boca Raton, USA: CRC Press. https://doi.org/10.1201/b16452

Ngoenchai, P. and Suwonsichon, T. (2011). Comparison of sorting task, Napping and Flash Profile in sensory descriptive of fried chili paste. Presented at $49^{\text {th }}$ Kasetsart University, Bangkok, 2011. Bangkok, Thailand: Kasetsart University.

Obilor, E.I. and Amadi, E.C. (2018). Test for significance of Pearson's correlation coefficient. International Journal of Innovative Mathematics, Statistics and Energy Policies, 6(1), 11-23.

Phrigboonchan, P. (2011). Fishery Product Technology. Phitsanulok: Pibulsongkram Rajabhat University.

Phornphisutthimas, S. (2010). Pilot-scale development of dried seasoning with Tom Yam flavour using mushroom as adsorbent. Asian Journal of Food and Agro-Industry, 3(3), 335-342

Popper, R. (2014). Use of Just About Right in Consumer Research. In Varela, P. and Ares, G. (Eds). Novel Techniques in Sensory Characterization and Consumer Profiling, p. 137-157. Boca Raton, USA: 
CRC Press. https://doi.org/10.1201/b16853-6

Prasertwaree, R. (2005). Menu Development of High Calcium Thai Diet. Na Khon Pratom, Thailand: Madidol University.

Resurreccion, A.V.A. (1998). Consumer Sensory Testing For Product Development. Gaithersburg, USA: Aspen Publication.

Siripongvutikorn, S., Thummaratwasik, P. and Huang, Y.W. (2005). Antimicrobial and antioxidation effects of Thai seasoning, Tom-Yum. LWT- Food Science and Technology, 38(4), 347-352. https:// doi.org/10.1016/j.lwt.2004.06.006

Srisawat, N. (2020). Salt Reduction for Health, Retrieved on November 7, 2020 from Mgronline Website: https://mgronline.com/goodhealth/ detail/9630000044450.

Sukhontachart, S. (2013). Activities based costing of dried shrimp production: a case study in Tha Sala district, Nakhon Sri Thammarat province. Surat Thani, Thailand: Walailak University.

Suwankanit, C., Pandolsook, S., Vittayaporn, V., Tohtubtiang, K. and Nantaragsa, N. (2015). Influences of different soup stocks on chemical and organoleptic properties of Tom Yum. Journal of Science and Technology, Ubon Ratchathani University, 17(3), 1-15.

Tirawanichakul, S., Na Phatthalung, W. and Tirawanichakul, Y. (2008). Drying strategy of shrimp using hot air convection and hybrid infrared radiation/hot air convection. Walailak Journal Science and Technology, 5(1), 77-100.

Whangchai, N., Ungsethaphand, T., Chitmanat, C., Mengumphan, K. and Uraiwan, S. (2007). Performance of giant freshwater prawn (Macrobrachium rosenbergii de Man) reared in Earthen ponds Beneath plastic film shelters Chiang Mai Journal of Science, 34(1), 89-96.

World Health Organization (WHO). (2012). Guideline: Sodium Intake for Adults and Children. Geneva, Switzerland: World Health Organization.

Yamprayoon, J. and Sukkho, A. (2006). Processing Effect on Quality of Dried Shrimp. Bangkok, Thailand: Department of Fisheries, Ministry of Agriculture and Cooperatives.

Zhu, M. (2018). Dried Shrimp. Retrieved on November 7, 2020 from Omnivorescookbook Website: https:// omnivorescookbook.com/dried-shrimp? fbclid=IwAR3HR2qLBegUHPajtGntEkegBKXP0Pu ctBtt xvys FLGiicT30psGafWdRLo. 